\title{
PUBLIC-PRIVATE PARTNERSHIP AT IMPLEMENTATION OF URBAN DEVELOPMENT PROJECTS
}

\author{
T. Daskalova* \\ University of National and World Economy, Sofia, Bulgaria
}

\begin{abstract}
Public-private partnership is a significant alternative for the local development. The projects based on this cooperation are main instruments for solution of social-economic and structural problems of the cities. The purpose of the publication is identification of the prerequisites, the problems and the possibilities for improvement of the elaboration and the implementation of projects for urban development in Bulgaria. Desk analysis, empirical analysis and other scientific methods are applied for the attainment of the purpose in the research. Main deficits are synthesized as a result of the analysis at an institutional and operational level of the public-private partnership. Perspectives for improvement of the potential for successful implementation of projects for sustainable development of the cities are outlined as conclusion.
\end{abstract}

Key words: projects for public-private partnership, sustainable local development

\section{INTRODUCTION}

The cooperation between the public and the private sector is not the sole possibility for development of the infrastructure and offering the public services related to it. It should be perceived as one of the great deal of alternatives for management of public infrastructural projects. The formation of these kinds of cooperation is determined predominantly by the insufficiently built-up infrastructure and the deficit of financial resources for the provision of the needed services of quality.

There are objective prerequisites for implementation of projects for public-private partnership (PPP) in Bulgaria. At an institutional level they are related to the legislation, the strategic framework and the use of the financial engineering, and at an operational level - to the results from the implementation of the projects.

The target of the research are the projects for PPP, implemented at a local level and the subject-matter are the legislative, the statutory and the financial aspects of the PPP.

Correspondence to: Tatyana Daskalova,

University of National and World Economy, Sofia

1700, tel. +35928195621, e-mail:

tdaskalova@unwe.bg
The purpose of this research is to determine the possibilities for improvement of the implementation of projects for PPP at an institutional and at an operational level. The following tasks are set up for the attainment of the purpose:

- Analysis of the strategic framework and the legislation regulating the PPP.

- Analysis of projects for PPP in six big cities from the second hierarchical level on the territory of the six districts for planning in Bulgaria during this programme period.

- Offering possibilities for improvement of the development and the implementation of projects of quality for the PPP.

The thesis of the research is that there are alternatives for the enhancement of the potential of the PPP for implementation of projects for sustainable urban development.

\section{PUBLIC-PRIVATE PARTNERSHIP - ALTERNATIVE OF THE LOCAL DEVELOPMENT}

In the conditions of increasing competition the limited public resources for implementation of investment designs and the possibilities for attainment of a reasonable compromise between justice and efficiency require that the municipalities should direct their policies at new approaches for infrastructural development. The cooperation between the 
DASKALOVA T.

public and the private sector at this stage is an alternative of significance, which opens up perspectives both for the local power and for the private investors. The formation of these kinds of cooperation is determined most of all by the insufficiently built-up infrastructure and by the financial difficulties of the municipalities to provide the needed services of quality. The international practice shows that the PPP is one of the successful financial instruments for provision of investments when the municipal budgets do not have the needed resource and wish to provide bigger value of the invested public funds. PPP may be a main instrument also for the reduction of the significant social-economic differences, which exist between the regions in the country, providing for simultaneously economic growth and enhancement of the welfare of the population.

The public-private partnership is a long-term contractual relationship between persons from the public and the private sector for buildingup infrastructural projects and for the provision of the services related to them [1]. It represents application of models and schemes of interaction between the state and the municipal institutions on the one hand and the enterprises of the private sector on the other hand, designated for better management of the public infrastructure and the municipal outlets and offering the relevant public services [2]. It is characteristic of these partnerships that the parties participating in them share the investments and the risk, the responsibility and the remuneration. The designation of such partnerships is different, but in the general event it includes financing, design, building up, management and maintenance of infrastructural projects [3].

Public-private partnership may be viewed as an alternative both of the monopoly of the public sector and of the full privatization. With this model the public and the private sectors acquire rights of ownership and joint responsibility in the provision of infrastructural services of quality. The logical basis of the PPP consists of the circumstance that both sectors - the public and the private ones, have unique characteristics, which provide them with advantages in specific aspects of the provision of services or the implementation of projects. The most successful schemes of partnerships are built up on the strong sides of the public and the private sector combined in supplementing each other relationships.
The public-private partnership is created aimed at the implementation of projects, provision of services or realization of activities which are traditionally offered by the public sector [4], with a view to the attainment of better quality of the services offered. This kind of cooperation may be viewed as a flexible mechanism for the implementation of longterm investment projects.

The main reason for the use of the PPP with priority pertaining to the traditional methods of contracting is its capability to bring better value of the funds invested at the provision of public services. The overall approach of the PPP at rendering the needed services, the distribution of the risks between the parties, the use of the skills and the experience of the private sector provide possibility for significant economies during the entire project cycle.

At this stage the creation of the following prerequisites of greater significance is needed for the successful realization of the partnerships at a local level:

- Application of the PPP on the basis of an appropriate and secure legislative and regulatory framework.

- Carrying out clearly defined municipal policy for the development of the cooperation between the public and the private sector.

- Encouragement of the application of the financial instruments under the operational programmes for rendering support to projects for PPP.

\section{LEGAL AND REGULATORY FRAMEWORK OF THE PUBLIC- PRIVATE PARTNERSHIP}

The legal measurement of the PPP is related to the existing legislation in the country regulating the contracts with the private sector. The Public-Private Partnership Act was applied during the period 2012-2017 in Bulgaria [5], which regulates their realization in practice. The adoption of the Act aims at the creation of unified rules for the PPP, secure legal environment and efficient competition. The application of the Act is directed at the provision of accessible and of high-quality services of public interest, through attainment of better value of the invested public funds. Further to that at providing possibility for encouragement of the private investments into the building up of the public infrastructure and at rendering public services. This on its hand, at creating guarantees for protection of the public assets and for efficient management of 
the public funds. The law for PPP sets up a statutory framework of the entire process, including a definition and characteristics of the PPP, the targets and the subjects of the partnership and the contractual relationships of the public and the private partners.

It is established for the short period of the Act that there are problematic moments in the practical application of the PPP. They are related to the limited scope of projects, through which activities of public interest are implemented - technical infrastructure, social infrastructure and the green system. No projects in strategic spheres as road network, airports, ports, energy sector and so on are included in the applied field of the PPP. There are no sufficient mechanisms which guarantee the conformity between the state and the municipal priorities in the sphere of the PPP. This makes the unified planning and adoption of a general concept for the PPP as a form of supplementing financing to the funds from the European Union (EU) difficult.

There is need of final development of the subordinate legislation, which should anticipate enough stimuli for initiative on the part of stakeholders and allow for the practical implementation of the projects for the PPP. The Register of PPP anticipated in the Act, by which publicity and transparency of the entire process should be provided, is not created.

In the absence of specialized legislation, the individual aspects of the PPP are regulated in some general acts and respectively in individual provisions of the private acts related to specific regulated matter. In some events the issuance of permits, certificates and others for the implementation of a certain economic activity is regulated, in other events - approval of investment projects, plans and so on.

For instance, the possibility of the municipalities to implement economic activity jointly with persons from the private sector is regulated in the Municipal Ownership Act [6]. The joint forms comprise: trading companies with municipal participation in the capital, civil companies and contracts for joint activity. The municipalities may participate in these forms with free pecuniary means and with properties which are private municipal ownership. The right of the municipalities to establish special rules for the joint economic activity carried out by them is regulated by an Ordinance.
The powers of the Municipal Council are defined in the Local Self-Government and Local Administration Act [7], amongst which the following are of the greatest significance for the PPP: the management of municipal property, the creation of trading companies with municipal property, the adoption of strategic and plan documents for development of the municipality, the participation in associations and so on. Possibility is anticipated with regard to the municipal cooperation for creation of associations for attainment of purposes of mutual interest on the grounds of a cooperation agreement signed. The creation of PPP directed at the following is also taken into consideration here, to wit: improvement of the quality of the provided services of mutual interest; attainment of more efficient spending of the financial and administrative resources of the municipality; realization of projects contributing to the overcoming of substantial problems at a local level.

Ordinances regulating the rules for partnership between the local power and the business were adopted in the municipalities on the grounds of this Act. The procedure and the conditions for their application in the municipality are regulated by the Ordinance on PPP. The purposes and the principles of the partnership are formulated and the forms and the spheres of cooperation of priority guaranteeing the public interest and protection of the interest of the private investor are determined. The document contains norms for the regime for determination of the partner, the rights and the obligations of the participants in the process and the administrative-criminal responsibility.

Due to the absence of adopted national methodologies for application of the PPP, Internal Rules and procedures for realization of the PPP were developed in a lot of municipalities with a view to the provision of methodological instructions for the municipal employees participating in the management of projects for the PPP. This document is of organizational-operational nature and presents the structure of the process for realization of the PPP. Conformity of the process with the law, regulation of the process, the rights and the responsibilities of the engaged officials, provision of the needed general information, methodology and practical means, as well as of a framework for making decisions in compliance with the best value of the funds unvested and tolerability for the budget are provided through the Internal Rules and 
DASKALOVA T.

procedures. The Internal Rules and procedures for realization of the PPP in the municipality contribute to the minimalization of the risks of technical-organizational errors at the implementation of the process for cretaion of such partnerships.

\section{LOCAL POLICY FOR PUBLIC-PRIVATE PARTNERSHIP}

The followed clearly defined and precise municipal policy in the sphere of the PPP is a substantial prerequisite for the realization of the PPP. The assessment of the attractiveness of this policy for the private sector is of primary significance. The political commitment at a strategic level is important for the private sector, which views the partnership as a permanent source of possibilities for the development of the business.

The municipal policy for development of the PPP is pursued through determination of realistic purposes, principles and specific measures for their attainment. At the development of the policy the local authorities initially formulate the concept for the PPP, and after that determine the sectors and the projects appropriate for this approach and integrated in the development plans, the sector strategies and the investment programmes. This allows for the better financial security of the projects and also renders assistance to the determination of the specific objectives which are to be achieved by these projects.

The purpose of the use of the PPP for the implementation of municipal policies is determined by the following circumstances: development of services of public interest of high quality and accessible; limited public resources for provision of public services; enhancement of the quality of management of the infrastructural projects; protection of the public assets and the efficient management of the public funds at the realization of the PPP.

The municipal policy for the PPP is determined by the Municipal Council through adoption of the municipal development plan. The municipal development plan considers issues in various scales, providing integrated direction of development of the territory and the local community. The plan binds the comparative advantages, the specific characteristics and the potential of the municipality. As a strategic document it determines vision, medium-term purposes and priorities for development directed at the attainment of a higher living standard of the population and sustainable development. The sources of funds for financing the priorities and the measures are determined in the indicative financial table of the municipal development plan - municipal budget, central budget, local public funds, funds of the European Union, private funds, companies, financial instruments.

The programme for realization of the municipal development plan provides the internal and the external coordination of the resources for realization of the plan, optimizes the possibilities for financing, identifies the institutional support and the technical assistance for implementation. The programme contains a package of specific measures for development and projects for their realization, the needed financial resources, the units and the institutions responsible for the carrying out of the projects and the time period of realization. The projects for PPP, the terms for their implementation and the amount of the financial funds for each individual project are also included in the programme.

There are weak sides at the elaboration of the municipal development plans and the programmes for their realization. The criteria for inclusion of projects for PPP are not described in detail in the plans, and the municipal PPPs are not differentiated in an independent section both in the plans and in the programmes, which makes the practical application of the PPP difficult.

The needed territorial basis for the anticipation of activities for local sustainable development is provided with the spatial plans of the municipality. The general and the detailed spatial plans create a planned basis for longterm spatial development of the territory bound to the documents for strategic planning. The spatial plans determine the functional organization, structure and building up of various in scope, contents and structure territorial units. These plans contain organizational measures for spatial development and application of the integrated policy for social-economic development at a local level. The structure and the designation of the territory are determined through these documents, the appropriate location and development of the infrastructure projects are anticipated.

The integrated plan for urban recovery and development represents a connection of the 
system for social-economic planning and that of the spatial planning. This plan combines the characteristic particularities of the strategic planning and the administrative structure. The integrated plan contains an aggregate of related in time and space projects, actions and investment intentions, which are applied in certain urban areas for effect. It integrates policies and unites diverse participants for their joint implementation contributing to the realization of the priorities for development determined in the strategic documents.

Depending on the administrative capacity and the potential for development of the city, the integrated plan may include specific zones for effect on the territory of the city: areas of predominating social nature, areas with potential for economic development, areas of public functions of high public significance. Specific priority and integrated projects are identified for each of the areas, through the realization of which the economic, social and ecological condition of the area is permanently improved.

The elaboration of the integrated plans is related to the application of the Operational Programme "Regional Development" (20072013) and of other operational programmes financing projects in the cities. Further to the means from the Structural Funds of the European Union, other financial mechanisms for implementation of the projects may also be applied. At the same time the integrated plan provides possibility for attraction of private capitals into projects of priority for the city and building up of PPP. In 2011 the city authorities commenced the elaboration of such plans which were approved by the Ministry of Regional Development and Public Works and entered into force at the end of 2013.

\section{FINANCIAL ENGINEERING AT URBAN PROJECTS FOR PUBLIC-PRIVATE PARTNERSHIP}

New policy of the EU for encouragement of the support for PPP through financial instruments is applied for the programme period 2014-2020. The projects for urban development in Bulgaria are financed under Operational Programme "Regions in Growth", directed at the development of the regions and rendering assistance to the purposes of the urban policy in Bulgaria. The Programme assists activities which contribute to the attainment of sustainable urban development, creation of favorable conditions for improvement of the quality of life and new work places in the cities. The carrying out of urban projects from the Integrated Urban Recovery and Development Plans is financed under Priority Axis 1 "Sustainable and Integrated Urban Development" (with budget in the amount of 840,4 million Euro). Investments are anticipated for: energy efficiency in residential and administrative buildings; development of the systems of the urban transport; improvement of the urban environment and of the areas with potential for economic development; renewal of social, educational, health, cultural and sports infrastructure [8]. Beneficiaries are 39 municipalities of big and of medium size towns from the $1^{\text {st }}$ to the $3^{\text {rd }}$ hierarchical level. They are determined as interim units with regard to the selection of the projects.

Support under the Programme is rendered in the form of gratuitous financing, financial instruments (loans and guarantees) and a combination of them for certain projects with insufficient financial viability. The advantages of the financial instruments to the gratuitous financial aid are reduced to attraction of private investments and provision of employment as well as to rendering assistance to the PPP. The provision of possibility for long-term investment credits is another advantage. A third advantage of no less significance is the stimulation of the credit institutions for participation in the public policies. It should be taken into consideration that during the next programme period the financial instruments will predominate to the grant financing and will exceed $50 \%$ of the financing from the Structural Funds of the EU. The support through financial instruments under Priority Axis 1 of the Programme is realized through Urban Development Fund for Sofia, for North Bulgaria and for South Bulgaria [9]. The Urban Development Fund is continuation of the initiative JESSICA from the preceding programme period, introduced as framework for encouragement of the application of the financial engineering for sustainable development of the cities. Their purpose is to improve the access to financing of admissible projects, simultaneously attracting an additional financial resource from private investors to the funds from the Programme. The funds for urban development are in the amount of 146 million Euro and represent low-interest long-term loans (with a term of up to 2035) with built-in guarantees. Crediting is project orientated and is granted most frequently in the form of project 
financing, but also of circulating capital, bridge financing, and in some events - share participation of the fund.

The funds are granted to municipalities, private investors and project companies. As compared to the preceding programme period the scope of the support with financial instruments under the operational programme is expanded, and the number of the cities, which they are applied in, is significantly increased. The financial mediators which manage the Urban Development Funds are:

- For the regions SOUTH and Sofia Association "Fund for Sustainable Cities". The projects for urban development are realized on the territory of 22 cities from South Bulgaria, and the project should get within a zone for impact from the integrated urban recovery and development plan or is amongst the projects which cooperate for the building up of the functional connections.

- For region North - "Regional Urban Development Fund". The projects are carried out on the territory of 17 cities in North Bulgaria.

A mandatory condition for rendering assistance to the urban projects from the two funds is that they should be in conformity with: the general and detailed spatial plans of the cities; the municipal development plans, as well as other plans, strategies and programmes at a local and regional level; the integrated urban recovery and development plans. Criteria for admissibility and criteria for selection of the urban projects are determined, the following of which are of greater significance, to wit: degree of project readiness, potential for generation of revenues, significance of social and economic impact, overall sustainability, economic viability.

Nine general priority spheres were identified, which are assisted by the financial instruments: Rehabilitation of buildings; sports facilities; culture and entertainment; investment in industrial zones; healing and health care institutions; market places and commercial areas; urban infrastructure; systems for sustainable urban transport; science and education.

For the period 2014-2019 from the six cities from the second hierarchical level - Burgas, Varna, Plovdiv, Varna, Burgas, Blagoevgrad, Veliko Tarnovo, Vidin, there are developed projects only in the first three cities (in the group of the biggest cities in the country). It is established from the analysis of the data published on the web site of the Regional Urban Development Fund [10] that the total number of the elaborated urban projects is 87 , of which 26 - from beneficiaries in Burgas, 35 - in Varna, and 26 - in Plovdiv.

Certain differences are observed with regard to the priority spheres of financing of the projects, which are determined by the specific social-economic characteristics of the cities. The projects in the following sectors are with the biggest number, to wit: Rehabilitation of buildings - 16 nos., 8 nos. of them being for the city of Varna; culture and entertainment 16 nos., of which 6 nos. for the cities of Burgas and Varna each; urban infrastructure - 15 nos., of which 7 nos. for the city of Varna and 6 nos. for the city of Plovdiv; investments in industrial zones - 12 nos., of which 7 nos. for the city of Burgas. There are no developed urban projects for Burgas with the sectors: market places and commercial areas, science and education, and for Plovdiv - market places and commercial areas.

The following four groups may be differentiated depending on the degree of development of the projects: projects at a conceptual stage; projects in the process of realization; completed projects; suspended projects. The total number of the urban projects in the first group - projects at a conceptual stage, is 30 nos., inclusive of for Burgas - 12 nos., Varna - 10 nos., and Plovdiv -8 nos. The projects getting within the second and the third group are with the smallest number. The projects which are in the process of realization are 7 nos., respectively for Burgas - 3 nos., Varna - 2 nos. and Plovdiv nos. The total number of the completed projects is 7 , and 4 nos. are carried out in Varna and 3 nos. - in Burgas. The number of the suspended projects is the biggest - 43, respectively for the cities of Varna - 18 nos., Plovdiv -17 nos. and Burgas -8 nos. The main reasons for the terminated contracts under the projects may be generalized in the following directions: proposed not sufficiently convincing business plan; obtained assessment for unacceptable risk; insecure economic potential; difficulties at structuring the financing; the location of the project is beyond the defined areas for impact.

The following conclusions may be drawn from the analysis: the capacity of the beneficiaries from the municipalities of Blagoevgrad, Veliko Tarnovo and Vidin at the search of financing 
of urban projects is insufficient; the number of the successfully implemented projects for urban development is small and insufficient number of projects with high public effect.

\section{CONCLUSION}

It is established as a result of the analysis that there is need of increase of the local potential for development and implementation of urban projects for PPP. Possibilities may be sought in two directions: at an institutional level elaboration of mechanisms for PPP in the segment for urban development, adoption of specialized legislation for the financial instruments, expansion of the territorial scope of the integrated plans of the cities; at an operational level - improvement of the capacity of the municipalities for management of urban projects for PPP through provision of technical assistance for preparation of projects of quality.

\section{REFERENCES}

1. Hristov, Hr., T. Daskalova, Public-Private Partnerships, Avangard Prima,, Sofia, 2013, ISBN 978-619-160-149-3.
DASKALOVA T.

2. Public Private Partnerships: A Guide for Local Government, Ministry of Municipal Affairs, British Columbia, May 1999.

3. Green Paper on Public-Private Partnerships and Community Law on Public Contracts and Concessions, European Commission, Brussels, April 2004.

4. Guidelines for successful public-privatepartnerships, European Commission, Directorate General Regional Policy, Brussels, January 2003.

5. https://www.lex.bg/laws/ldoc/2135798101

6. https://www.lex.bg/bg/mobile/ldoc/213387 4691

7. https://www.lex.bg/bg/mobile/ldoc/213258 0865

8. https://www.eufunds.bg/bg/oprd/node/693 Operational Program "Regions in Growth"

9. http://www.fmfib.bg/bg/fi/20-finansiranesas-spodelyane-na-riska/12-fond-zagradsko-razvitie - Urban Development Fund

10.http://jessicafund.bg/bg/ - Regional Urban Development Fund 